\title{
REVIEW
}

\section{Cardiovascular disease in systemic sclerosis - an emerging association?}

\author{
Gene-Siew Ngian*1,2, Joanne Sahhar ${ }^{3}$, lan P Wicks ${ }^{1,2}$ and Sharon Van Doornum ${ }^{1,2}$
}

\begin{abstract}
Microvascular disease is a prominent feature of systemic sclerosis (SSC) and leads to Raynaud's phenomenon, pulmonary arterial hypertension, and scleroderma renal crisis. The presence of macrovascular disease is less well established, and, in particular, it is not known whether the prevalence of coronary heart disease in SSc is increased. Furthermore, in terms of cardiac involvement in SSc, there remains conjecture about the relative contributions of atherosclerotic macrovascular disease and myocardial microvascular disease. In this review, we summarize the literature describing cardiovascular disease in SSc, discuss the pathophysiological mechanisms common to SSc and atherosclerosis, and review the surrogate markers of cardiovascular disease which have been examined in SSc. Proposed mediators of the vasculopathy of SSC which have also been implicated in atherosclerosis include endothelial dysfunction, a reduced number of circulating endothelial progenitor cells, and an increased number of microparticles. Excess cardiovascular risk in SSc is suggested by increased arterial stiffness and carotid intima thickening and reduced flow-mediated dilatation. Cohort studies of adequate size are required to resolve whether this translates into an increased incidence of cardiovascular events in patients with SSC.
\end{abstract}

\section{Introduction}

Patients with systemic inflammatory conditions such as systemic lupus erythematosus (SLE) and rheumatoid arthritis (RA) have been shown to develop premature and accelerated atherosclerosis $[1,2]$, but it remains unclear

\footnotetext{
*Correspondence: gngian@student.unimelb.edu.au

'The University of Melbourne, Department of Medicine (Royal Melbourne Hospital/Western Hospital), 4th Floor, Clinical Sciences Building, Royal Melbourne Hospital, Royal Parade, Parkville, Victoria 3050, Australia

Full list of author information is available at the end of the article
}

whether this occurs in systemic sclerosis (SSc). Involvement of the microvasculature is one of the earliest features of SSc, preceding and potentially contributing via tissue ischemia to the widespread fibrosis characteristic of this condition. Pathological changes include disruption of the endothelium, mononuclear cell infiltration of the vessel wall, frank obliterative lesions, and progressive loss of capillaries. There is also disruption of neuroendothelial control mechanisms of vascular tone. These microvascular abnormalities contribute to the pathogenesis of pulmonary arterial hypertension (PAH), scleroderma renal crisis, Raynaud's phenomenon, and digital ulceration.

Although macrovascular disease was not originally considered a feature of SSc, multiple studies have revealed an increased prevalence of large-vessel disease of the upper and lower limbs in patients with SSc $[3,4]$. The prevalence of coronary artery and cerebrovascular disease in SSc, however, remains unclear. The purposes of this review are to summarize the evidence for macrovascular disease, cardiovascular risk factors, and surrogate measures of cardiovascular disease in SSc and to explore potential pathogenic mechanisms of accelerated atherosclerosis in patients with SSc.

\section{Clinical cardiovascular disease Peripheral vascular disease}

Peripheral vascular disease in patients with SSc has been reported in uncontrolled observational studies that used techniques such as the ankle brachial pressure index (ABPI), lower-limb Doppler ultrasound, and angiography [5-7]. Two studies have compared the prevalence of peripheral vascular disease in patients with SSc with that in controls. Veale and colleagues [3] measured the prevalence of intermittent claudication in a cohort of 46 patients with SSc by using a validated World Health Organization questionnaire and compared the findings with those of the Edinburgh Artery Study, a crosssectional population-based study of a neighboring region. The rates of prevalence of intermittent claudication were 21.7\% in the SSc cohort and 4.5\% in the Edinburgh Artery Study. Although the two groups were not directly comparable, the authors suggested that the size of the difference and the fact that the SSc cohort was younger 
and predominantly female strengthened the significance of their findings. The authors went on to perform a case control study of 54 patients with SSc and 43 age- and sexmatched controls [4]. Peripheral vascular disease, as diagnosed by the ABPI, was present in $17 \%$ of patients with SSc and in none of the controls $(P=0.003)$ [4]. There was no difference in the traditional cardiovascular risk factor profile between the two groups.

The contribution of traditional cardiovascular risk factors to peripheral vascular disease was examined in a retrospective review of 26 angiograms performed in a single SSc cohort [5]. The authors demonstrated a significant association between the presence of traditional cardiovascular risk factors and proximal, but not distal, vascular disease in the lower limb. Though limited by a small sample size, this study suggests that, in at least some cases, peripheral vascular disease in SSc is not atherosclerotic but related to the vasculopathy of SSc itself. In keeping with this possibility, Youssef and colleagues [8] reported chronic obliterative thromboangiitis on histological examination of an amputated limb in a woman with limited SSc. Involvement of the vasa vasorum has been suggested as a potential cause of macrovascular disease in SSc [9].

\section{Cerebrovascular disease}

Few studies have investigated the prevalence of cerebrovascular disease in SSc. Youssef and colleagues [8] performed a retrospective cohort study comparing the prevalence of macrovascular disease in 31 patients with limited SSc and 31 matched controls. Cerebrovascular disease was defined as a transient ischemic attack or completed stroke diagnosed by a physician, the presence of carotid or vertebral artery bruits, Doppler evidence of carotid or vertebral artery disease, or angiographic evidence of carotid artery stenosis. The investigators found no significant difference in cerebrovascular disease between patients with SSc and controls (26\% versus $19 \%$, respectively; $P=0.544$ ). In contrast, Ho and colleagues [4] examined the prevalence of carotid artery disease by using B mode and color Doppler ultrasound and demonstrated carotid artery stenosis in 64\% of patients with SSc and $35 \%$ of age- and sex-matched controls $(P=0.007)$.

\section{Cardiac disease}

\section{Coronary artery disease}

Early autopsy studies of patients with SSc suggested that atherosclerotic disease of the coronary arteries was infrequent. Several case series demonstrated myocardial infarction (MI) in the presence of patent coronary arteries, suggesting primary myocardial disease or vasospasm $[10,11]$. The most quoted of these studies was a retrospective review of 52 autopsies of patients with SSc; in that review, 26 (50\%) patients were found to have foci of myocardial necrosis [11]. Of these 26 patients, 23 had widely patent extramural coronary arteries. A common pattern in those with myocardial involvement was contraction band necrosis, which is a histopathological correlate of reperfusion injury. The authors therefore hypothesized that the observed myocardial damage was due to intermittent hypoperfusion of the myocardium secondary to Raynaud's phenomenon of the intramural coronary arteries. It is important to note that these autopsy studies were performed in an era when SSc was largely untreated and patients were more likely to succumb to SSc-related complications such as scleroderma renal crisis. This temporal change is reflected in an analysis of mortality over a 30-year period from 1972 to 2002 , in which 10 -year survival improved from $54 \%$ to $66 \%$ and non-SSc-related deaths increased from $20 \%$ to $50 \%$ of all deaths [12].

There are no large cohort studies examining the prevalence of coronary artery disease in living patients with SSc. Most studies to date have reported the presence of coronary atherosclerosis in SSc patients who undergo coronary angiography for clinical indications. For example, Akram and colleagues [13] reviewed all 172 coronary angiograms performed in a single SSc referral center from 1998 to 2004 and found coronary artery disease in $22 \%$. These authors calculated standardized prevalence ratios based on age, gender, and presenting cardiac symptom and, using published probability tables relating pretest likelihood of coronary artery disease to angiographic abnormalities, concluded that the prevalence of coronary artery disease was no greater than that expected in individuals without SSc. This was, however, a retrospective study with no control group. Furthermore, patients included in the study had differing indications for angiography and the number of patients undergoing angiogram for suspected coronary artery disease was not reported. When grouped according to predominant cardiac symptom, only 27 patients had typical angina, 29 had atypical angina, and 116 had dyspnea on exertion. There was also a very high prevalence of PAH $(63 \%$ of patients with limited disease and $85 \%$ of patients with diffuse disease), perhaps accounting for a significant proportion of reported symptoms. This was therefore a study of a highly selected group rather than consecutive patients with SSc.

The relationship between clinical events and coronary angiogram findings was examined in a retrospective review of all SSc patients admitted to a single institution with acute MI over a 20-year period [14]. MI was defined as electrocardiographic changes and an at least twofold increase in serum myocardial creatinine kinase (CK) level. The authors identified 11 patients, 3 of whom had normal coronary arteries on cardiac catheterization. The odds ratio of finding normal coronary arteries in acute 
MI was 34 (95\% confidence interval of 14 to 81 ) for patients with SSc compared with the general population. Of the 11 cases, however, 7 had significant renal impairment and 4 had frank scleroderma renal crisis. This may affect the validity of these results given that the clearance of CK is reduced in renal failure and an elevated CK formed part of the definition of MI.

Another angiographic study assessed the overlap between PAH and coronary artery disease [15]. One hundred twenty consecutive patients with SSc were assessed clinically for cardiorespiratory disease. Both right heart catheterization and coronary angiography were performed for suspected PAH in 20 patients and for suspected coronary artery disease in 10 patients. There was considerable overlap of diagnoses; $\mathrm{PAH}$ was found in 12 of the 20 suspected PAH cases and in 2 of the 10 suspected coronary artery disease cases. Similarly, coronary artery stenosis was found in 9 of the 20 suspected PAH cases and in 6 of the 10 suspected coronary artery disease cases. All eight of the patients who underwent revascularization for coronary artery disease improved significantly in 6-minute walk distance and the Borg dyspnea index. The authors concluded that coronary artery disease symptoms may be atypical in patients with SSc and that revascularization may improve symptoms and physical activity in selected patients.

Few angiographic studies have been performed in asymptomatic patients with SSc. Tarek and colleagues [16] performed coronary catheterization in 9 patients with diffuse SSc and 5 patients with limited SSc, all of whom were female and asymptomatic. The authors detected a total of 19 angiographic abnormalities, with significant coronary artery stenosis in 3 patients with limited disease. Other angiographic findings included coronary artery ectasia, slow flow, tortuosity, calcification, and spasm. The prevalence of traditional cardiovascular risk factors in this cohort was low, with hypertension in 3 patients but no other risk factors of note. While the study was small and uncontrolled, the findings suggest that angiographic abnormalities may be higher than previously thought in asymptomatic patients with SSc.

\section{Primary myocardial disease}

Microvascular disease of the myocardium can also result in angina pectoris or acute MI (or both) in SSc. It has been proposed that recurrent vasospasm, together with irreversible structural lesions, leads to repeated focal ischemia and eventual myocardial fibrosis [17]. When advanced, this manifests as systolic and diastolic dysfunction, leading in some cases to overt congestive cardiac failure. Myocardial perfusion in SSc has been found to be impaired by using cardiac catheterization [18], radionuclide imaging [19], and echocardiographic techniques [20]. One study of 26 unselected patients with diffuse SSc found evidence of cardiac abnormalities on thalliumperfusion scanning in 20 patients, only 6 of whom had symptomatic cardiac disease [19]. Of the 7 patients who had exercise-induced defects and who underwent subsequent coronary angiography, all had normal coronary arteries. Furthermore, patients with exerciseinduced defects that were more significant had lower left and right ventricular ejection fractions on radionuclide ventriculography. This led the authors to conclude that abnormalities of myocardial perfusion in SSc are due to a disturbance of the myocardial microcirculation and that this, in turn, contributes to ventricular dysfunction.

In recent years, modalities that are more sensitive have been developed to detect primary myocardial involvement in SSc. Non-standard echocardiographic techniques such as pulsed tissue Doppler and strain rate imaging better quantify regional myocardial function than standard echocardiography. Cardiac magnetic resonance imaging (MRI) has been used to image myocardial fibrosis in SSc [21]; however, histological confirmation of areas of MRI signal abnormality is lacking. N-terminal pro-brain natriuretic peptide (NT-proBNP) is an amino acid produced from cleavage of the prohormone proBNP, which is released from the heart in response to pressure or volume overload or both. In the general population, it has diagnostic and prognostic value in heart failure and other cardiovascular diseases [22]. In SSc, NT-proBNP has been investigated as a biomarker of primary myocardial disease and is elevated in patients with primary myocardial dysfunction as determined by tissue Doppler echocardiography [23]. It has the advantage of being easily performed and widely applied; however, it is not specific for primary myocardial disease, as it is also elevated in PAH.

\section{Surrogate markers of atherosclerosis}

Various surrogate markers of atherosclerosis have been investigated in SSc but with conflicting results.

\section{Carotid intima-media thickness}

Carotid intima-media thickness (CIMT) as measured by high-resolution ultrasound is a well-validated marker of subclinical atherosclerosis. Increased CIMT has been shown to correlate with traditional cardiovascular risk factors and to predict future vascular events in healthy individuals [24]. A meta-analysis of CIMT in rheumatic diseases, including RA, SLE, and SSc, found that CIMT was significantly increased in this population compared with healthy, age- and sex-matched controls [25]. The pooled result of the SSc studies demonstrated a greater CIMT in patients with SSc than controls, suggesting an increased prevalence of subclinical atherosclerosis. The effect size seen in SSc was also greater than those in RA and SLE. Despite this finding, a number of individual 
Table 1. Studies of carotid intima-media thickness in systemic sclerosis

\begin{tabular}{|c|c|c|c|c|c|c|}
\hline Reference & $\begin{array}{l}\text { Total SSc, } \\
\text { number }\end{array}$ & $\begin{array}{l}\text { ISSc, } \\
\text { number }\end{array}$ & $\begin{array}{l}\text { dSSc, } \\
\text { number }\end{array}$ & $\begin{array}{l}\text { Controls, } \\
\text { number }\end{array}$ & Outcome $^{a}$ & Other findings \\
\hline Lekakis et al. [40], 1998 & 12 & 0 & 12 & 12 & $\uparrow$ & \\
\hline Cheng et al. [30], 2003 & 52 & 33 & 19 & 21 & $\leftrightarrow$ & \\
\hline Zakopoulos et al. [29], 2003 & 40 & 15 & 30 & 45 & $\leftrightarrow$ & \\
\hline Bartoli et al. [32], 2007 & 53 & 45 & 8 & 53 & $\uparrow$ & $\begin{array}{l}\text { CIMT is higher in patients carrying } D \text { allele of ACE } \\
\text { gene. }\end{array}$ \\
\hline Bartoli et al. [38], 2007 & 35 & 11 & 24 & 20 & $\uparrow$ & $\begin{array}{l}\text { No correlation between CIMT and cardiovascular } \\
\text { risk factors was found. }\end{array}$ \\
\hline Sherer et al. [34], 2007 & 44 & 38 & 6 & 32 & $\uparrow$ & CIMT is higher in patients with IgM anti-HSP-65. \\
\hline Szucs et al. [28], 2007 & 29 & 19 & 10 & 29 & $\leftrightarrow$ & CIMT correlates with age and disease duration. \\
\hline Roustit et al. [27], 2008 & 42 & 33 & 9 & 33 & $\leftrightarrow$ & \\
\hline Hettema et al. [26], 2008 & 49 & 45 & 4 & 32 & $\leftrightarrow$ & \\
\hline Liu et al. [31], 2011 & 25 & 17 & 8 & 25 & $\leftrightarrow$ & \\
\hline
\end{tabular}

a Carotid intima-media thickness (CIMT) in patients with systemic sclerosis (SSc) relative to controls: $\uparrow$, CIMT higher in patients with SSc than controls; $\leftrightarrow$, no difference in CIMT between patients and controls. ACE, angiotensin-converting enzyme; anti-HSP-65, anti-heat shock protein-65; D, deletion; dSSc, diffuse systemic sclerosis; ISSc, limited systemic sclerosis.

studies have found no increase in CIMT in patients with SSc (Table 1) [26-31].

Correlates of increased CIMT have also been assessed in several studies. Bartoli and colleagues [32] demonstrated increased CIMT in patients with SSc and found an association between higher CIMT and the deletion (D) polymorphism of the angiotensin-converting enzyme (ACE) gene. The ACE DD genotype has been shown to be associated with atherosclerosis in the general population [33]. Another group has demonstrated an association between increased CIMT in patients with SSc and the presence of antibodies to heat-shock protein-65 [34], which are also implicated in the pathogenesis of atherosclerosis.

\section{Flow-mediated dilatation}

Flow-mediated dilatation (FMD) is a marker of endothelium-dependent vasodilatation and is measured using high-resolution ultrasound at the brachial artery. In healthy arteries exposed to a short period of occlusion by tourniquet, restoration of blood flow results in transient vasodilatation. Impaired FMD is associated with the presence of traditional cardiovascular risk factors [35] and is independently predictive of incident cardiovascular events [36]. FMD is usually performed in concert with nitrate-mediated dilatation, which is assessed after sublingual nitroglycerin administration and reflects endothelium-independent vasodilatation. Many, but not all, studies have found FMD to be decreased in SSc compared with controls (Table 2) [27,28,37-44]. Some groups have found nitrate-mediated dilatation to be reduced also [40,41,45], and this could suggest a coexisting functional or structural abnormality of arterial smooth muscle, adventitia, or both. Interestingly, in the studies in which no difference in FMD was detected, the majority of patients had limited rather than diffuse disease $[27,44]$, suggesting more endothelial dysfunction in diffuse SSc.

\section{Arterial stiffness}

Arterial stiffness is measured by the techniques of pulse wave analysis (PWA) and pulse wave velocity (PWV), and carotid-femoral PWV is considered the current 'goldstandard' measurement of arterial stiffness [46]. PWA, expressed as the augmentation index (AI), reflects the stiffness of the aorta, whereas carotid-femoral PWV reflects the velocity of the pulse wave along the aortic and aorto-iliac pathways. Increased arterial stiffness results in premature return of reflected waves in late systole, causing increased load on the left ventricle and increased myocardial oxygen demand. Arterial stiffness is increased in the presence of cardiovascular risk factors [47] and is an independent predictor of cardiovascular events and cardiovascular and all-cause mortality across a wide range of patient populations [48].

Arterial stiffness has been examined in SSc but with varying results (Table 3) [27,31,37,39,44,49,50]. Cypiene and colleagues [37] found arterial stiffness as measured by PWA and PWV to be elevated in 17 patients with diffuse SSc compared with 34 healthy controls. Timar and colleagues [49] found that AI and PWV were both elevated in 40 patients with SSc and in 35 controls. The investigators also found that PWV was higher in patients with limited disease than in those with diffuse disease and that PWV was positively correlated with disease duration. The authors therefore postulated that PWV may be a better measure of arterial stiffness than AI in SSc. Another group found arterial stiffness to be elevated in patients with SSc or mixed connective tissue disease 
Table 2. Studies of flow-mediated dilatation in systemic sclerosis

\begin{tabular}{|c|c|c|c|c|c|c|}
\hline Reference & $\begin{array}{l}\text { Total SSc, } \\
\text { number }\end{array}$ & $\begin{array}{l}\text { ISSC, } \\
\text { number }\end{array}$ & $\begin{array}{l}\text { dSSc, } \\
\text { number }\end{array}$ & $\begin{array}{l}\text { Controls, } \\
\text { number }\end{array}$ & Outcome $^{a}$ & Other findings \\
\hline Lekakis et al. [40], 1998 & 12 & 0 & 12 & 12 & $\downarrow$ & $\begin{array}{l}\text { NMD } \downarrow \text {. Improvement was found in FMD after } \\
\text { estrogen administration. }\end{array}$ \\
\hline Andersen et al. [44], 2002 & 24 & 20 & 4 & 24 & $\leftrightarrow$ & NMD $\leftrightarrow$ \\
\hline D'Andrea et al. [42], 2007 & 33 & 18 & 15 & 33 & $\downarrow$ & $\begin{array}{l}\text { NMD } \leftrightarrow \text {. FMD was a predictor of middle LV strain } \\
\text { on TTE. }\end{array}$ \\
\hline Szucs et al. [28], 2007 & 29 & 19 & 10 & 29 & $\downarrow$ & $\mathrm{NMD} \leftrightarrow$ \\
\hline Sfikakis et al. [39], 2007 & 24 & 6 & 18 & 52 & $\downarrow$ & $\begin{array}{l}\text { NMD } \leftrightarrow \text {. Four weeks of bosentan led to } \\
\text { improvement in FMD. }\end{array}$ \\
\hline Bartoli et al. [38], 2007 & 35 & 24 & 11 & 20 & $\downarrow$ & $\begin{array}{l}\text { No correlation between FMD and cardiovascular } \\
\text { risk factors was found. }\end{array}$ \\
\hline Roustit et al. [27], 2008 & 42 & 33 & 9 & 33 & $\leftrightarrow$ & $\mathrm{NMD} \leftrightarrow$ \\
\hline Rollando et al. [43], 2010 & 43 & 30 & 13 & 27 & $\downarrow$ & $\begin{array}{l}\text { FMD was inversely correlated with microvascular } \\
\text { damage on nailfold videocapillaroscopy. }\end{array}$ \\
\hline Rossi et al. [45], 2010 & 14 & 10 & 4 & 14 & $\downarrow$ & NMD $\downarrow$ \\
\hline
\end{tabular}

aFlow-mediated dilatation (FMD) in patients with systemic sclerosis (SSc) relative to controls: $\downarrow$, lower in patients with SSc than controls; $\leftrightarrow$, no difference between patients with SSc and controls. dSSc, diffuse systemic sclerosis; ISSc, limited systemic sclerosis; LV, left ventricle; NMD, nitroglycerin-mediated dilatation; TTE, trans-thoracic echocardiography.

Table 3. Studies of arterial stiffness in systemic sclerosis

\begin{tabular}{|c|c|c|c|c|c|c|}
\hline Reference & $\begin{array}{c}\text { Total SSc, } \\
\text { number }\end{array}$ & $\begin{array}{c}\text { ISSc, } \\
\text { number }\end{array}$ & $\begin{array}{l}\text { dSSc, } \\
\text { number }\end{array}$ & $\begin{array}{l}\text { Controls, } \\
\text { number }\end{array}$ & Outcome $^{\mathrm{a}}$ & Other findings \\
\hline Andersen et al. [44], 2002 & 24 & 20 & 4 & 24 & $\mathrm{Al} \uparrow$ & \\
\hline Sfikakis et al. [39], 2007 & 24 & 6 & 18 & 52 & $\mathrm{Al} \leftrightarrow$ & $\begin{array}{l}\text { Four weeks of bosentan therapy had no effect on } \\
\text { Al. }\end{array}$ \\
\hline Roustit et al. [27], 2008 & 42 & 33 & 9 & 33 & PWV $\leftrightarrow$ & \\
\hline Cypiene et al. [37], 2008 & 17 & 0 & 17 & 34 & $\begin{array}{l}\mathrm{Al} \uparrow \\
\mathrm{PWV} \uparrow\end{array}$ & \\
\hline Timar et al. [49], 2008 & 40 & 31 & 9 & 35 & $\begin{array}{l}\mathrm{Al} \uparrow \\
\mathrm{PWV} \uparrow\end{array}$ & $\begin{array}{l}\text { PWV was higher in patients with limited disease } \\
\text { and correlated with disease duration. }\end{array}$ \\
\hline Peled et al. [50], 2009 & 18 & & & 13 & $\mathrm{Al} \leftrightarrow$ & $\begin{array}{l}\text { No difference was found between patients with } \\
\text { SSC with and without PAH. }\end{array}$ \\
\hline Liu et al. [31], 2011 & 25 & 17 & 8 & 25 & $\begin{array}{l}\mathrm{PWV} \uparrow \text { at } \\
\text { forearm and arm }\end{array}$ & PWV $\leftrightarrow$ at upper arm, aorta, and leg \\
\hline
\end{tabular}

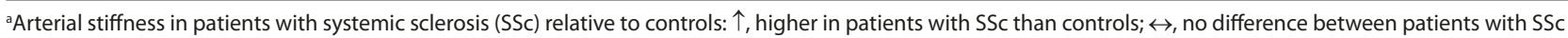
and controls. Al, augmentation index; dSSc, diffuse systemic sclerosis; ISSc, limited systemic sclerosis; PAH, pulmonary arterial hypertension; PWV, pulse wave velocity.

and that arterial stiffness correlated with elevated levels of soluble markers of endothelial activation, including plasma nitrate, soluble E-selectin, and soluble vascular cell adhesion molecule-1 (VCAM-1) [44]. Liu and colleagues [31] found regional differences in arterial stiffness with increased PWV in the forearm and arm but not the upper arm, aorta, or leg in patients with SSc compared with controls. This suggests preferential involvement of the muscular arteries of the forearm [31]. Several other studies have been unable to demonstrate a significant difference in arterial stiffness between patients with SSc and controls [27,50].

\section{Coronary calcium score}

A novel method of assessing coronary artery disease is the coronary calcium score, as determined by multidetector computed tomography. This technique measures coronary artery calcification that occurs in atherosclerotic plaque. In a cross-sectional study of 17 patients with SSc free from clinical cardiovascular disease and 17 controls, coronary calcification was present in 9 patients with SSc and 3 controls $(P=0.03)$ [51]. The correlation between coronary calcification and angiographic findings in the SSc population is unknown and larger studies are required to investigate this association. 


\section{Cardiovascular risk factors in systemic sclerosis}

There is limited information regarding the prevalence of traditional cardiovascular risk factors in SSc. A study of 40 patients with SSc and 45 controls demonstrated no difference in blood pressure on 24-hour ambulatory blood pressure monitoring [29]. Significantly lower levels of high-density lipoprotein were recorded in one study of 24 female patients with limited SSc compared with 24 healthy controls [52], whereas another study found significantly elevated lipoprotein [a] in 31 female patients with SSc compared with 33 healthy controls but no significant difference in other cholesterol parameters or triglycerides [53]. Other novel cardiovascular risk factors that have been reported as elevated in SSc include oxidized lowdensity lipoprotein and endothelin [54].

\section{Potential mechanisms of cardiovascular disease in systemic sclerosis}

Inflammation

Inflammation is a key component of atherosclerosis [55], and it is well established that even a relatively minor elevation of inflammatory markers (such as C-reactive protein) is predictive of cardiovascular events in the general population [56]. Cardiovascular disease occurs more frequently in patients with chronic inflammatory diseases such as SLE [1] and RA [2] than in the general population, and although the precise mechanism of accelerated atherosclerosis in these conditions has not been fully elucidated, various cellular and cytokine pathways have been implicated. Excess cytokine production and release are also key events in the pathogenesis of SSc. Numerous inflammatory mediators that have been implicated in the pathogenesis of atherosclerosis, including tumor necrosis factor-alpha, interleukin-6, and highsensitivity $\mathrm{C}$-reactive protein, have been demonstrated to be increased in patients with SSc compared with controls [57]. The relationship between these mediators and cardiovascular disease in SSc is unclear; however, it is possible that chronic systemic inflammation could promote accelerated atherosclerosis in patients with SSc.

\section{Endothelial dysfunction}

Endothelial dysfunction is a component of the pathophysiology of both SSc and atherosclerosis (Figure 1). In $\mathrm{SSc}$, the initiating injury is unknown, but endothelial cell damage leads to enhanced expression of adhesion molecules and elevated levels of circulating soluble adhesion molecules. Soluble E-selectin, intercellular adhesion molecule-1, and VCAM-1 levels are all significantly increased in SSc, reflecting endothelial activation [58]. Enhanced endothelial cell expression of adhesion molecules results in adhesion of inflammatory cells, transmigration across the vessel wall, and infiltration of the extracellular matrix. Another important component of endothelial dysfunction in SSc is derangement of vasoactive mediators, with an increase in vasoconstrictive endothelin and a decrease in the vasodilator nitric oxide (NO).

In atherosclerosis, endothelial cell dysfunction is the common pathway by which factors such as elevated lowdensity lipoprotein, elevated plasma homocysteine, various infectious agents, and exposure to free radicals from smoking, hypertension, and diabetes mellitus are proposed to contribute to pathogenesis [55]. Endothelial dysfunction leads to upregulation of adhesion molecules on the endothelium and increased vessel wall permeability. Lipid-laden monocytes and macrophages known as foam cells then accumulate. Migration and proliferation of vascular smooth-muscle cells follow, leading to remodeling of the vessel wall and atherosclerotic plaque formation.

\section{Endothelial progenitor cells}

A reduction in the density of blood vessels is one of the hallmarks of vascular disease in SSc. Paradoxically, this occurs in the setting of increased circulating angiogenic factors, such as vascular endothelial growth factor [59]. Several theories have been advanced to account for the deficient angiogenesis in SSc despite the presence of permissive vascular growth factors. One explanation is a reduction in circulating endothelial progenitor cells (EPCs). Asahara and colleagues [60] isolated a population of progenitor cells from human peripheral blood which were incorporated into sites of new blood vessel formation when adoptively transferred to an animal model of ischemia. Whereas Kuwana and colleagues [61] initially showed that EPCs were decreased in SSc, others [62] have since demonstrated that these cells are elevated in early disease and decrease with increasing disease duration. EPCs have also been the subject of study in cardiovascular disease, in which a decreased number in the peripheral circulation has been shown to be predictive of recurrent acute coronary artery events [63].

Nevskaya and colleagues [64] examined the relationship between cardiovascular disease and EPCs in 40 patients with SSc and found that a decreased EPC count correlated with endothelial dysfunction, as measured by FMD. Decreased EPC number did not, however, correlate with subclinical atherosclerosis as measured by CIMT [64]. There was also no relationship between EPC count and the Framingham risk factor score or the presence of traditional cardiovascular risk factors.

Although EPCs are a promising potential biomarker of both cardiovascular risk and SSc disease activity, there is some debate over their true significance. Some groups have questioned whether the cells isolated by Asahara and colleagues [60] and others are true progenitor cells that incorporate into new blood vessels or rather are cells 


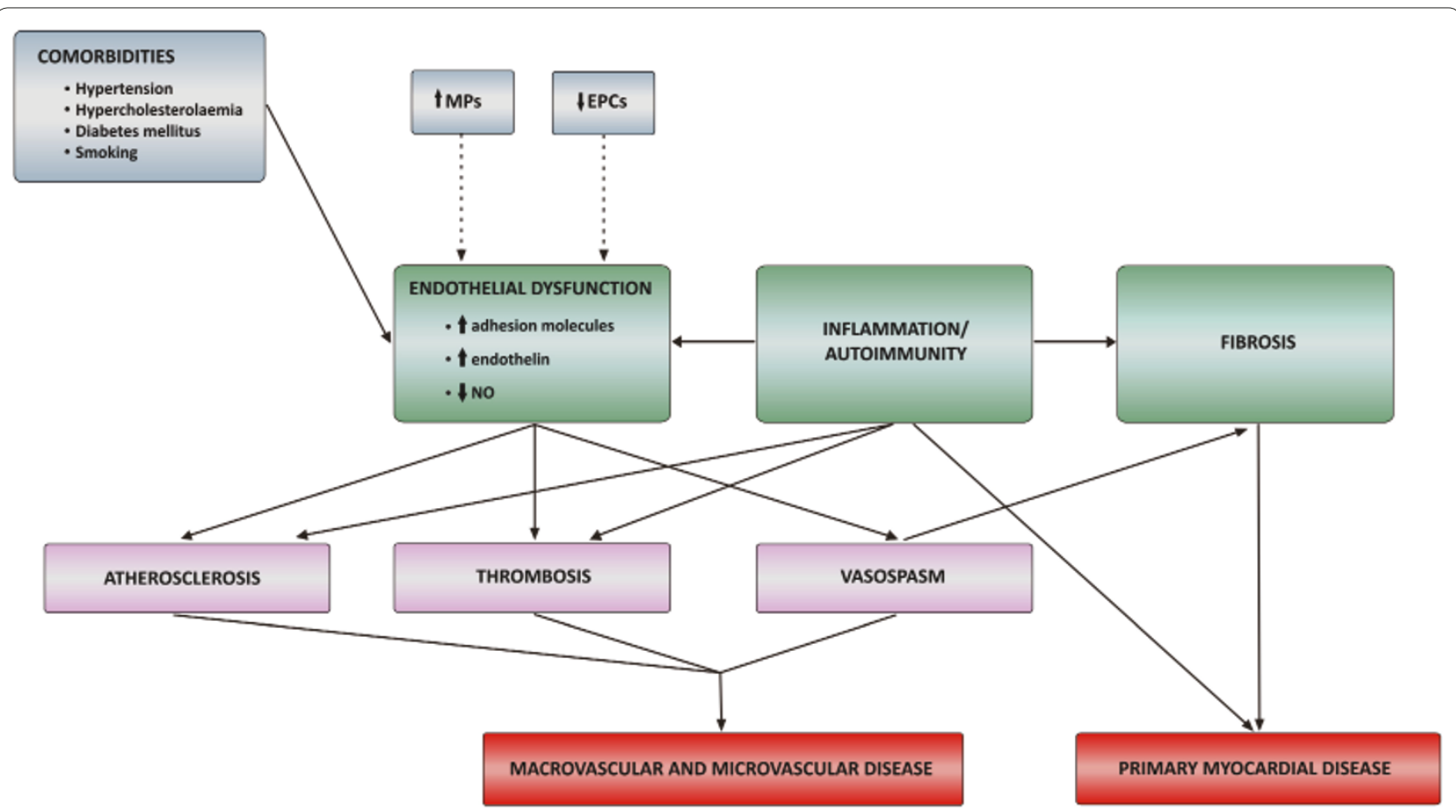

Figure 1. Potential factors contributing to the pathogenesis of cardiovascular disease in systemic sclerosis. EPC, endothelial progenitor cell; MP, microparticle; NO, nitric oxide.

of hemotopoietic lineage which have a paracrine effect on blood vessel formation [65]. The development of cell lineage markers that are more specific will help elucidate the biological properties of these cells.

\section{Microparticles}

Microparticles (MPs) are small circulating membranecoated vesicles that are important mediators of intercellular signaling. MPs contribute to the immunopathogenesis of various thrombotic and rheumatic diseases via their role in the regulation of inflammation, thrombosis, and angiogenesis. MPs arise from a variety of cell types and are formed by the process of blebbing during cell activation and apoptosis. MP numbers have been shown to be elevated in patients with SSc and to correlate with the presence of interstitial lung disease [66]. In SSc, MPs have been identified to arise from platelets, endothelial cells, monocytes, and $\mathrm{T}$ cells, reflecting activation of these cells. MPs have also been suggested as a biomarker of coronary artery disease. High levels of endothelial MPs are found in patients with acute MI and result in severe endothelial dysfunction by selectively impairing the production of NO [67].

\section{Angiotensin-converting enzyme insertion/deletion polymorphism}

Activation of the renin-angiotensin-aldosterone axis is central to the pathogenesis of scleroderma renal crisis, as demonstrated by the dramatic improvement in survival since ACE inhibitors have been used to treat the condition. Over a 30-year period that spanned the introduction of ACE inhibitors, deaths due to renal crisis decreased from $42 \%$ to $6 \%(P<0.005)[12]$.

An insertion/deletion (I/D) polymorphism of the ACE gene has been identified, and the highest levels of plasma $\mathrm{ACE}$ are associated with the DD genotype and lowest levels are associated with the II genotype [68]. The original report of the relationship between this polymorphism and acute MI found a risk ratio of 1.34 (95\% confidence interval of 1.05 to 1.70 ) for MI in those with the DD genotype compared with those with either the II or ID genotype [33]. A later meta-analysis of studies concluded that the risk conferred by the DD genotype was more modest (risk ratio of 1.0 to 1.1) [69]. As described earlier, the ACE gene polymorphism has been examined in patients with SSc; in this study, the presence of a D allele correlated with increased CIMT [32]. These investigators also reported a correlation between the presence of a $\mathrm{D}$ allele and an increased risk of SSc in the Italian population [70]; however, this finding has not been confirmed in other populations [71].

\section{Antiphospholipid antibodies}

The presence of anticardiolipin (aCL) or anti- $\beta_{2}$-glycoprotein I (anti- $\beta_{2}$ GPI) antibodies or both in the absence of antiphospholipid syndrome or other autoimmune 
disease has been examined as an independent risk factor for ischemic heart disease. A study of incident cardiovascular events in a population of Hawaiian men of Japanese descent found that anti- $\beta_{2}$ GPI in the presence of aCL was independently predictive of incident ischemic stroke and MI over 20 years of follow-up [72]. In a study of recurrent cardiac events post-infarction, elevated IgG $\mathrm{aCL}$ and low IgM aCL, but not anti- $\beta_{2} \mathrm{GPI}$, were independent risk factors for recurrent events [73].

An increased prevalence of aCL and anti- $\beta_{2}$ GPI antibodies occurring in the absence of typical clinical manifestations of antiphospholipid syndrome has been demonstrated in patients with SSc compared with controls [74]. Boin and colleagues [75] showed that anti$\beta_{2}$ GPI is associated with both higher mortality and vascular disease, including digital ischemia and $\mathrm{PAH}$, in SSc. The authors did not report on the cause of mortality or the prevalence of cardiovascular disease in their cohort.

\section{Conclusions}

Since the introduction of ACE inhibitors for the management of scleroderma renal crisis in the 1980s, the overall survival of patients with SSc has improved significantly and the relative contribution to mortality of non-SSc comorbidities has increased [12]. With better therapies for $\mathrm{PAH}$, we are likely to see further improvements in survival and non-SSc-related organ dysfunction become more apparent. Patients with other chronic inflammatory diseases such as SLE and RA experience excess cardiovascular disease, predominantly due to accelerated atherosclerosis, and this may occur in SSc also. Given the prominent involvement of the vasculature in SSc and the role of inflammation in the development of atherosclerosis, overlap between these disorders might not be that surprising. However, there is a relative paucity of data regarding clinical and preclinical cardiovascular disease in SSc, whether due to atherosclerosis or microvascular involvement. In particular, adequately sized population-based cohort studies of the incidence and prevalence of coronary artery disease in SSc relative to the general population are lacking. Surrogate markers of cardiovascular disease may assist in quantifying the burden of subclinical atherosclerosis and may also provide insights into the mechanisms underlying the development of macrovascular disease in SSc. Recognition of such an association could have important clinical ramifications.

\section{Abbreviations}

$A B P I$, ankle brachial pressure index; $A C E$, angiotensin-converting enzyme; $\mathrm{aCL}$, anticardiolipin; Al, augmentation index; anti- $\beta_{2} \mathrm{GPI}$, anti- $\beta_{2}$-glycoprotein I; CIMT, carotid intima-media thickness; $C K$, creatinine kinase; $D$, deletion; EPC, endothelial progenitor cell; FMD, flow-mediated dilatation; I, insertion; MI, myocardial infarction; MP, microparticle; MRI, magnetic resonance imaging: $\mathrm{NO}$, nitric oxide; NT-proBNP, N-terminal pro-brain natriuretic peptide; PAH, pulmonary arterial hypertension; PWA, pulse wave analysis; PWV, pulse wave velocity; RA, rheumatoid arthritis; SLE, systemic lupus erythematosus; SSC, systemic sclerosis; VCAM-1, vascular cell adhesion molecule-1.

\section{Competing interests}

The authors declare that they have no competing interests.

\section{Authors' contributions}

GSN conducted the literature review and drafted the manuscript. JS, IW, and SVD read, revised, and approved the final manuscript.

\section{Author details}

'The University of Melbourne, Department of Medicine (Royal Melbourne Hospital/Western Hospital), 4th Floor, Clinical Sciences Building, Royal Melbourne Hospital, Royal Parade, Parkville, Victoria 3050, Australia. ${ }^{2}$ Royal Melbourne Hospital, Grattan Street, Parkville, Victoria 3050, Australia. ${ }^{3}$ Monash Medical Centre, 246 Clayton Road, Clayton, Victoria 3168, Australia.

\section{Published: 26 August 2011}

\section{References}

1. Hak AE, Karlson EW, Feskanich D, Stampfer MJ, Costenbader KH: Systemic lupus erythematosus and the risk of cardiovascular disease: results from the nurses' health study. Arthritis Rheum 2009, 61:1396-1402.

2. Solomon DH, Karlson EW, Rimm EB, Cannuscio CC, Mandl LA, Manson JE, Stampfer MJ, Curhan GC: Cardiovascular morbidity and mortality in women diagnosed with rheumatoid arthritis. Circulation 2003, 107:1303-1307.

3. Veale DJ, Collidge TA, Belch JJ: Increased prevalence of symptomatic macrovascular disease in systemic sclerosis. Ann Rheum Dis 1995, 54:853-855.

4. Ho M, Veale D, Eastmond C, Nuki G, Belch J: Macrovascular disease and systemic sclerosis. Ann Rheum Dis 2000, 59:39-43.

5. Dick EA, Aviv R, Francis I, Hamilton G, Baker D, Black C, Platts A, Watkinson A: Catheter angiography and angioplasty in patients with scleroderma. $\mathrm{Br} J$ Radiol 2001, 74:1091-1096.

6. Wan MC, Moore T, Hollis S, Herrick AL: Ankle brachial pressure index in systemic sclerosis: influence of disease subtype and anticentromere antibody. Rheumatology (Oxford) 2001, 40:1102-1105.

7. Youssef $\mathrm{P}$, Englert $\mathrm{H}$, Bertouch J: Large vessel occlusive disease associated with CREST syndrome and scleroderma. Ann Rheum Dis 1993, 52:464-466.

8. Youssef $\mathrm{P}$, Brama T, Englert H, Bertouch J: Limited scleroderma is associated with increased prevalence of macrovascular disease. J Rheumatol 1995, 22:469-472.

9. Kahaleh MB, LeRoy EC: Autoimmunity and vascular involvement in systemic sclerosis (SSC). Autoimmunity 1999, 31:195-214.

10. D'Angelo WA, Fries JF, Masi AT, Shulman LE: Pathologic observations in systemic sclerosis (scleroderma). A study of fifty-eight autopsy cases and fifty-eight matched controls. Am J Med 1969, 46:428-440.

11. Bulkley BH, Ridolfi RL, Salyer WR, Hutchins GM: Myocardial lesions of progressive systemic sclerosis. A cause of cardiac dysfunction. Circulation 1976, 53:483-490.

12. Steen VD, Medsger TA: Changes in causes of death in systemic sclerosis, 1972-2002. Ann Rheum Dis 2007, 66:940-944.

13. Akram MR, Handler CE, Williams M, Carulli MT, Andron M, Black CM, Denton CP, Coghlan JG: Angiographically proven coronary artery disease in scleroderma. Rheumatology (Oxford) 2006, 45:1395-1398.

14. Derk CT, Jimenez SA: Acute myocardial infarction in systemic sclerosis patients: a case series. Clin Rheumatol 2007, 26:965-968.

15. Komocsi A, Pinter T, Faludi R, Magyari B, Bozo J, Kumanovics G, Minier T, Radics J, Czirjak L: Overlap of coronary disease and pulmonary arterial hypertension in systemic sclerosis. Ann Rheum Dis 2010, 69:202-205.

16. Tarek EG, Yasser AE, Gheita T: Coronary angiographic findings in asymptomatic systemic sclerosis. Clin Rheumatol 2006, 25:487-490.

17. Allanore $Y$, Meune C: Primary myocardial involvement in systemic sclerosis: evidence for a microvascular origin. Clin Exp Rheumatol 2010, 28:S48-53.

18. Kahan A, Nitenberg A, Foult JM, Amor B, Menkes CJ, Devaux JY, Blanchet F, Perennec J, Lutfalla G, Roucayrol JC: Decreased coronary reserve in primary scleroderma myocardial disease. Arthritis Rheum 1985, 28:637-646.

19. Follansbee WP, Curtiss El, Medsger TA Jr., Steen VD, Uretsky BF, Owens GR, Rodnan GP: Physiologic abnormalities of cardiac function in progressive 
systemic sclerosis with diffuse scleroderma. N Engl J Med 1984, 310:142-148.

20. Montisci R, Vacca A, Garau P, Colonna P, Ruscazio M, Passiu G, lliceto S, Mathieu A: Detection of early impairment of coronary flow reserve in patients with systemic sclerosis. Ann Rheum Dis 2003, 62:890-893.

21. Tzelepis GE, Kelekis NL, Plastiras SC, Mitseas P, Economopoulos N, Kampolis C, Gialafos EJ, Moyssakis I, Moutsopoulos HM: Pattern and distribution of myocardial fibrosis in systemic sclerosis - A delayed enhanced magnetic resonance imaging study. Arthritis Rheum 2007, 56:3827-3836.

22. Januzzi JL, van Kimmenade R, Lainchbury J, Bayes-Genis A, Ordonez-Llanos J, Santalo-Bel M, Pinto YM, Richards M: NT-proBNP testing for diagnosis and short-term prognosis in acute destabilized heart failure: an international pooled analysis of 1256 patients: the International Collaborative of NT-proBNP Study. Eur Heart J 2006, 27:330-337

23. Allanore $Y$, Meune $\mathrm{C}$ : N-terminal pro brain natriuretic peptide: the new cornerstone of cardiovascular assessment in systemic sclerosis. Clin Exp Rheumatol 2009, 27:59-63.

24. Lorenz MW, Markus HS, Bots ML, Rosvall M, Sitzer M: Prediction of clinical cardiovascular events with carotid intima-media thickness: a systematic review and meta-analysis. Circulation 2007, 115:459-467.

25. Tyrrell PN, Beyene J, Feldman BM, McCrindle BW, Silverman ED, Bradley TJ: Rheumatic disease and carotid intima-media thickness: a systematic review and meta-analysis. Arterioscler Thromb Vasc Biol 2010, 30:1014-1026.

26. Hettema ME, Zhang D, de Leeuw K, Stienstra Y, Smit AJ, Kallenberg CG, Bootsma $\mathrm{H}$ : Early atherosclerosis in systemic sclerosis and its relation to disease or traditional risk factors. Arthritis Res Ther 2008, 10:R49.

27. Roustit M, Simmons GH, Baguet JP, Carpentier P, Cracowski JL: Discrepancy between simultaneous digital skin microvascular and brachial artery macrovascular post-occlusive hyperemia in systemic sclerosis. J Rheumatol 2008, 35:1576-1583

28. Szucs G, Timar O, Szekanecz Z, Der H, Kerekes G, Szamosi S, Shoenfeld Y, Szegedi G, Soltesz P: Endothelial dysfunction precedes atherosclerosis in systemic sclerosis--relevance for prevention of vascular complications. Rheumatology (Oxford) 2007, 46:759-762.

29. Zakopoulos NA, Kotsis VT, Gialafos EJ, Papamichael CM, Pitiriga V, Mitsibounas DN, Mavrikakis ME: Systemic sclerosis is not associated with clinical or ambulatory blood pressure. Clin Exp Rheumato/ 2003, 21:199-204.

30. Cheng KS, Tiwari A, Boutin A, Denton CP, Black CM, Morris R, Hamilton G, Seifalian AM: Carotid and femoral arterial wall mechanics in scleroderma. Rheumatology (Oxford) 2003, 42:1299-1305.

31. Liu J, Zhang Y, Cao T, Duan Y, Yuan L, Yang Y, Li Y, Yao L: Preferential macrovasculopathy in systemic sclerosis detected by regional pulse wave velocity from wave intensity analysis. Arthritis Care Res (Hoboken) 2011 63:579-587

32. Bartoli F, Angotti C, Fatini C, Conforti ML, Guiducci S, Blagojevic J, Melchiorre D, Fiori G, Generini S, Damjanov N, Rednic S, Pignone A, Castellani S, Abbate R, Matucci Cerinic M: Angiotensin-converting enzyme I/D polymorphism and macrovascular disease in systemic sclerosis. Rheumatology (Oxford) 2007, 46:772-775.

33. Cambien F, Poirier O, Lecerf L, Evans A, Cambou JP, Arveiler D, Luc G, Bard JM, Bara L, Ricard S, Tiret L, Amouyel P, Alhenc-Gelas F, Soubrier F: Deletion polymorphism in the gene for angiotensin-converting enzyme is a potent risk factor for myocardial infarction. Nature 1992, 359:641-644.

34. Sherer Y, Cerinic MM, Bartoli F, Blagojevic J, Conforti ML, Gilburd B, Ehrenfeld $M$, Shoenfeld $Y$ : Early atherosclerosis and autoantibodies to heat-shock proteins and oxidized LDL in systemic sclerosis. Ann N Y Acad Sci 2007 , 1108:259-267.

35. Celermajer DS, Sorensen KE, Bull C, Robinson J, Deanfield JE: Endotheliumdependent dilation in the systemic arteries of asymptomatic subjects relates to coronary risk factors and their interaction. J Am Coll Cardiol 1994, 24:1468-1474.

36. Yeboah J, Crouse JR, Hsu FC, Burke GL, Herrington DM: Brachial flowmediated dilation predicts incident cardiovascular events in older adults: the Cardiovascular Health Study. Circulation 2007, 115:2390-2397.

37. Cypiene A, Laucevicius A, Venalis A, Dadoniene J, Ryliskyte L, Petrulioniene Z, Kovaite M, Gintautas J: The impact of systemic sclerosis on arterial wall stiffness parameters and endothelial function. Clin Rheumatol 2008 27:1517-1522

38. Bartoli F, Blagojevic J, Bacci M, Fiori G, Tempestini A, Conforti ML, Guiducci S, Miniati I, Di Chicco M, Del Rosso A, Perfetto F, Castellani S, Pignone A, Cerinic MM: Flow-mediated vasodilation and carotid intima-media thickness in systemic sclerosis. Ann N Y Acad Sci 2007, 1108:283-290

39. Sfikakis PP, Papamichael C, Stamatelopoulos KS, Tousoulis D, Fragiadaki KG, Katsichti P, Stefanadis C, Mavrikakis M: Improvement of vascular endothelial function using the oral endothelin receptor antagonist bosentan in patients with systemic sclerosis. Arthritis Rheum 2007, 56:1985-1993.

40. Lekakis J, Mavrikakis M, Papamichael C, Papazoglou S, Economou O, Scotiniotis I, Stamatelopoulos K, Vemmos C, Stamatelopoulos S, Moulopoulos $S$ : Short-term estrogen administration improves abnormal endothelial function in women with systemic sclerosis and Raynaud's phenomenon. Am Heart J 1998, 136:905-912.

41. Lekakis J, Papamichael C, Mavrikakis M, Voutsas A, Stamatelopoulos S: Effect of long-term estrogen therapy on brachial arterial endotheliumdependent vasodilation in women with Raynaud's phenomenon secondary to systemic sclerosis. Am J Cardiol 1998, 82:1555-1557, A8.

42. D'Andrea A, Stisi S, Caso P, di Uccio FS, Bellissimo S, Salerno G, Scarafile R, Riegler L, Cuomo S, Citro R, Scherillo M, Calabro R: Associations between left ventricular myocardial involvement and endothelial dysfunction in systemic sclerosis: noninvasive assessment in asymptomatic patients. Echocardiography 2007, 24:587-597.

43. Rollando D, Bezante GP, Sulli A, Balbi M, Panico N, Pizzorni C, Negrini S, Brunelli C, Barsotti A, Cutolo M, Indiveri F, Ghio M: Brachial artery endothelial-dependent flow-mediated dilation identifies early-stage endothelial dysfunction in systemic sclerosis and correlates with nailfold microvascular impairment. J Rheumato/ 2010, 37:1168-1173.

44. Andersen GN, Mincheva-Nilsson L, Kazzam E, Nyberg G, Klintland N, Petersson AS, Rantapaa-Dahlqvist S, Waldenstrom A, Caidahl K: Assessment of vascular function in systemic sclerosis: indications of the development of nitrate tolerance as a result of enhanced endothelial nitric oxide production. Arthritis Rheum 2002, 46:1324-1332.

45. Rossi P, Granel B, Marziale D, Le Mée F, Francès Y: Endothelial function and hemodynamics in systemic sclerosis. Clin Physiol Funct Imaging 2010 30:453-459.

46. Laurent S, Cockcroft J, Van Bortel L, Boutouyrie P, Giannattasio C, Hayoz D, Pannier B, Vlachopoulos C, Wilkinson I, Struijker-Boudier H: Expert consensus document on arterial stiffness: methodological issues and clinical applications. Eur Heart J 2006, 27:2588-2605.

47. Oliver JJ, Webb DJ: Noninvasive assessment of arterial stiffness and risk of atherosclerotic events. Arterioscler Thromb Vasc Biol 2003, 23:554-566.

48. Vlachopoulos C, Aznaouridis K, Stefanadis C: Prediction of cardiovascular events and all-cause mortality with arterial stiffness: a systematic review and meta-analysis. J Am Coll Cardiol 2010, 55:1318-1327.

49. Timar O, Soltesz P, Szamosi S, Der H, Szanto S, Szekanecz Z, Szucs G: Increased arterial stiffness as the marker of vascular involvement in systemic sclerosis. J Rheumatol 2008, 35:1329-1333.

50. Peled N, Shitrit D, Fox BD, Shlomi D, Amital A, Bendayan D, Kramer MR: Peripheral arterial stiffness and endothelial dysfunction in idiopathic and scleroderma associated pulmonary arterial hypertension. J Rheumatol 2009, 36:970-975.

51. Khurma V, Meyer C, Park GS, McMahon M, Lin J, Singh RR, Khanna D: A pilot study of subclinical coronary atherosclerosis in systemic sclerosis: coronary artery calcification in cases and controls. Arthritis Rheum 2008, 59:591-597.

52. Borba EF, Borges CT, Bonfa E: Lipoprotein profile in limited systemic sclerosis. Rheumatol Int 2005, 25:379-383.

53. Lippi G, Caramaschi P, Montagnana M, Salvagno GL, Volpe A, Guidi G: Lipoprotein [a] and the lipid profile in patients with systemic sclerosis. Clin Chim Acta 2006, 364:345-348.

54. Hettema ME, Bootsma H, Kallenberg CG: Macrovascular disease and atherosclerosis in SSc. Rheumatology (Oxford) 2008, 47:578-583.

55. Ross R: Atherosclerosis--an inflammatory disease. N Engl J Med 1999 340:115-126.

56. Danesh J, Wheeler JG, Hirschfield GM, Eda S, Eiriksdottir G, Rumley A, Lowe GD, Pepys MB, Gudnason V: C-reactive protein and other circulating markers of inflammation in the prediction of coronary heart disease. NEngl J Med 2004, 350:1387-1397.

57. Baraut J, Michel L, Verrecchia F, Farge D: Relationship between cytokine profiles and clinical outcomes in patients with systemic sclerosis. Autoimmun Rev 2010, 10:65-73.

58. Andersen GN, Caidahl K, Kazzam E, Petersson AS, Waldenstrom A, MinchevaNilsson L, Rantapaa-Dahlqvist S: Correlation between increased nitric oxide production and markers of endothelial activation in systemic sclerosis: 
findings with the soluble adhesion molecules E-selectin, intercellular adhesion molecule 1, and vascular cell adhesion molecule 1. Arthritis Rheum 2000, 43:1085-1093.

59. Distler O, Distler JH, Scheid A, Acker T, Hirth A, Rethage J, Michel BA, Gay RE, Muller-Ladner U, Matucci-Cerinic M, Plate KH, Gassmann M, Gay S: Uncontrolled expression of vascular endothelial growth factor and its receptors leads to insufficient skin angiogenesis in patients with systemic sclerosis. Circ Res 2004, 95:109-116.

60. Asahara T, Murohara T, Sullivan A, Silver M, van der Zee R, Li T, Witzenbichler B, Schatteman G, Isner JM: Isolation of putative progenitor endothelial cells for angiogenesis. Science 1997, 275:964-967.

61. Kuwana M, Okazaki Y, Yasuoka H, Kawakami Y, Ikeda Y: Defective vasculogenesis in systemic sclerosis. Lancet 2004, 364:603-610.

62. Del Papa N, Cortiana M, Comina DP, Maglione W, Silvestri I, Maronetti Mazzeo L, Fracchiolla N, Fantini F, Cortelezzi A: Endothelial progenitor cells in systemic sclerosis: their possible role in angiogenesis. Reumatismo 2005, 57:174-179

63. Werner N, Kosiol S, SchiegI T, Ahlers P, Walenta K, Link A, Bohm M, Nickenig G: Circulating endothelial progenitor cells and cardiovascular outcomes. N Engl J Med 2005, 353:999-1007.

64. Nevskaya T, Bykovskaia S, Lyssuk E, Shakhov I, Zaprjagaeva M, Mach E, Ananieva L, Guseva N, Nassonov E: Circulating endothelial progenitor cells in systemic sclerosis: relation to impaired angiogenesis and cardiovascular manifestations. Clin Exp Rheumatol 2008, 26:421-429.

65. Yoder MC, Mead LE, Prater D, Krier TR, Mroueh KN, Li F, Krasich R, Temm CJ, Prchal JT, Ingram DA: Redefining endothelial progenitor cells via clonal analysis and hematopoietic stem/progenitor cell principals. Blood 2007, 109:1801-1809.

66. Nomura S, Inami N, Ozaki Y, Kagawa H, Fukuhara S: Significance of microparticles in progressive systemic sclerosis with interstitial pneumonia. Platelets 2008, 19:192-198.

67. Boulanger CM, Scoazec A, Ebrahimian T, Henry P, Mathieu E, Tedgui A, Mallat $\mathrm{Z}$ : Circulating microparticles from patients with myocardial infarction cause endothelial dysfunction. Circulation 2001, 104:2649-2652.

68. Rigat B, Hubert C, Alhenc-Gelas F, Cambien F, Corvol P, Soubrier F: An insertion/deletion polymorphism in the angiotensin l-converting enzyme gene accounting for half the variance of serum enzyme levels. J Clin Invest 1990, 86:1343-1346.
69. Keavney B, McKenzie C, Parish S, Palmer A, Clark S, Youngman L, Delepine M, Lathrop M, Peto R, Collins R: Large-scale test of hypothesised associations between the angiotensin-converting-enzyme insertion/deletion polymorphism and myocardial infarction in about 5000 cases and 6000 controls. International Studies of Infarct Survival (ISIS) Collaborators. Lancet 2000, 355:434-442.

70. Fatini C, Gensini F, Sticchi E, Battaglini B, Angotti C, Conforti ML, Generini S, Pignone A, Abbate R, Matucci-Cerinic M: High prevalence of polymorphisms of angiotensin-converting enzyme (I/D) and endothelial nitric oxide synthase (Glu298Asp) in patients with systemic sclerosis. Am J Med 2002, 112:540-544

71. Wipff J, Gallier G, Dieude P, Avouac J, Tiev K, Hachulla E, Granel B, Diot E, Sibilia J, Mouthon L, Meyer O, Kahan A, Varret M, Boileau C, Allanore Y: Angiotensinconverting enzyme gene does not contribute to genetic susceptibility to systemic sclerosis in European Caucasians. J Rheumatol 2009, 36:337-340.

72. Brey RL, Abbott RD, Curb JD, Sharp DS, Ross GW, Stallworth CL, Kittner SJ: beta(2)-Glycoprotein 1-dependent anticardiolipin antibodies and risk of ischemic stroke and myocardial infarction: the honolulu heart program. Stroke 2001, 32:1701-1706.

73. Bili A, Moss AJ, Francis CW, Zareba W, Watelet LF, Sanz I: Anticardiolipin antibodies and recurrent coronary events: a prospective study of 1150 patients. Thrombogenic Factors, and Recurrent Coronary Events Investigators. Circulation 2000, 102:1258-1263.

74. Sanna G, Bertolaccini ML, Mameli A, Hughes GR, Khamashta MA, Mathieu A: Antiphospholipid antibodies in patients with scleroderma: prevalence and clinical significance. Ann Rheum Dis 2005, 64:1795-1796.

75. Boin F, Franchini S, Colantuoni E, Rosen A, Wigley FM, Casciola-Rosen L: Independent association of anti-beta(2)-glycoprotein I antibodies with macrovascular disease and mortality in scleroderma patients. Arthritis Rheum 2009, 60:2480-2489.

doi:10.1186/ar3445

Cite this article as: Ngian GS, et al:: Cardiovascular disease in systemic sclerosis - an emerging association? Arthritis Research \& Therapy 2011, 13:237. 